\title{
Gonococcal septicaemia presenting as a subcutaneous abscess
}

\author{
N OBOTH OWINO,* D GOLDMEIER, † AND R A WALL \\ From the *Medical Unit, Hospital for Tropical Diseases, and the Departments of + Genitourinary \\ Medicine and \$Microbiology, University College Hospital, London
}

SUMMARY In a case of disseminated gonococcal infection the diagnosis was delayed until Neisseria gonorrhoeae was grown from pus from a discharging abscess of the biceps muscle. This unusual skin manifestation appears not to have been reported before.

\section{Introduction}

Disseminated gonococcal infection commonly presents with skin lesions, arthritis, and pyrexia. ${ }^{1-5}$ Such a case with an unusual skin manifestation-a large subcutaneous gonococcal abscess-is reported here.

\section{Case report}

A previously healthy 32-year-old African man felt unwell with occipital headache and pain in his neck and wrists 10 days after returning to Britain from Lesotho. The following day both wrists and hands became swollen and his right shoulder began to ache. The headache and neck and shoulder pain continued intermittently, while his wrists and hands became progressively swollen, stiff, and painful. He had no rigors, drowsiness, or urinary symptoms. Seven days after his initial symptoms he was admitted to the Hospital for Tropical Diseases.

\section{CLINICAL FINDINGS}

He was a fit-looking man with a diffuse, warm, tender, non-pitting swelling of both hands and wrists but not of the fingers. Active and passive movements at the wrists and metacarpophalangeal joints were severely limited and painful. His temperature was $37.5^{\circ} \mathrm{C}$, pulse rate $80 / \mathrm{min}$, and blood pressure $180 / 110 \mathrm{mmHg}$. A grade 2 systolic murmur was heard all over the praecordium. Heart size and fundi were normal. The liver was soft, tender, and enlarged to $3 \mathrm{~cm}$ below the right costal margin. Further thorough examination showed no other abnormality.

Address for reprints: Dr N O Owino, Medical Unit, Hospital for Tropical Diseases, 4 St Pancras Way, London NW1 OPE

Accepted for publication 14 August 1980

\section{LABORATORY FINDINGS}

The haemoglobin was $13 \mathrm{~g} / \mathrm{dl}$, white cell count $11.8 \times 109 / 1-78 \%$ neutrophils, $15 \%$ lymphocytes, $6 \%$ monocytes, and $1 \%$ eosinophils-and erythrocyte sedimentation rate $100 \mathrm{~mm} /$ first hour. No malarial parasites were found on serial blood films. Alanine transaminase was $77 \mathrm{IU} / \mathrm{l}$, aspartate transaminase 72 $\mathrm{IU} / \mathrm{l}$, total serum proteins $81 \mathrm{~g} / \mathrm{l}$, and globulins $40 \mathrm{~g} / \mathrm{l}$; serum alpha one and two and gamma globulins were both raised; creatinine kinase was $190 \mathrm{IU} / \mathrm{l}$ and ASO titre $<200 \mathrm{IU} / \mathrm{l} / \mathrm{ml}$. Blood cultures were sterile on all occasions.

The following values and test results were within normal limits or were negative: serum urea and electrolytes, immunoglobulins, uric acid, Treponema pallidum haemagglutination assay (TPHA) and rapid plasma reagin (RPR) test, serological tests for Entamoeba histolytica, and Filaria, Schistosoma, and Brucella species, creatinine clearance, Mantoux test, electrocardiograph (ECG), $x$-ray films of the chest, hands, shoulders, and neck, and intravenous pyelography. HLA-B27, rheumatoid factor, antinuclear factor (ANF), and serum autoantibodies were not found. Urine microscopy and culture gave negative results as did the sickle test.

\section{COURSE OF ILLNESS}

On the seventh day after admission the patient's right upper arm became swollen and the right elbow and shoulder increasingly painful and stiff. The region over the right biceps muscle was especially swollen and warm to the touch with localised pitting oedema. The heart murmur remained unchanged. On the sixteenth day the swelling over the right biceps muscle was fluctant. It was explored under general anaesthesia and showed straw-coloured fluid in a subcutaneous cavity superficial to the biceps muscle. Muscle and skin biopsy specimens were taken. 
Cultures of both fluid and curettings from the cavity were sterile; there were no acid-fast bacilli.

Histology of the muscle biopsy specimen showed non-specific myositis, and the skin specimen was histologically normal. Five days after exploration pus from the discharging wound grew Staphylococcus aureus and a "light growth" of Neisseria gonorrhoeae. Urethral and rectal swabs taken at this time (day 27) both grew $N$ gonorrhoeae, although even at this stage there was no clinical evidence of genital or rectal gonorrhoea. The isolate was sensitive to penicillin, tetracycline, and kanamycin by disc tests. Culture of throat specimens gave negative results. When questioned, the patient admitted to having had a transient urethral discharge on the tenth day after admission but had failed to report it at the time. He had had sexual intercourse with two different partners in Lesotho three weeks, and again five days, before the onset of his symptoms but denied homosexual contact. Cultures for Chlamydia trachomatis gave negative results from the urethra and rectum.

Twenty-six days after admission his left foot and ankle became swollen, painful, warm, and tender, but $x$-ray films were normal. No joint aspirate was obtained.

\section{TREATMENT}

Treatment was begun with a loading dose of penicillin G 5 megaunits intramuscularly and $1 \mathrm{~g}$ probenecid followed by penicillin $G 1$ megaunit intramuscularly with probenecid $500 \mathrm{mg}$ four times daily for three days. Thereafter he was given oral ampicillin $1 \mathrm{~g}$ with probenecid $500 \mathrm{mg}$ four times daily for a total of five days. His intermittent fever ceased after two days of antibiotic therapy. The joint swellings and stiffness subsided within a week, after which he was able to walk and use his hands almost normally. The heart murmur, which had remained unchanged before treatment, disappeared five days after penicillin was given. No gonococci were grown from urethral and rectal swabs taken five days after treatment had begun and on subsequent occasions.
He was discharged 40 days after admission with residual swelling, pain, and stiffness of the right hand, right shoulder, and wrists.

$\mathrm{He}$ was given doxycycline $200 \mathrm{mg}$ daily for one week for a residual nongonococcal urethritis. Two weeks after discharge all the affected joints were almost normal except for slight impairment of grip in the right hand and slight intermittent aching of the wrists. At seven weeks he was clinically normal. The abscess had healed completely.

\section{Comment}

Skin manifestations may sometimes not be apparent in disseminated gonococcal infection. Fever and 0 arthritis may suggest infectious or tropical disease. ${ }^{25}$ In the case described the discharging abscess cavity was found to contain gonococci. Even at this stage, the patient had no obvious clinical signs or symptoms of genital or rectal gonorrhoea. Once diagnosed and treated the patient responded rapidly and completely. To our knowledge the clinical picture of disseminated gonococcal infection with a large subcutaneous abscess has hitherto not been described.

We thank Professor A W Woodruff, for allowing us to report this case and for his helpful and constructive comments, and Dr J D Oriel, for his help in preparing the manuscript.

\section{References}

1. Abu-Nassar H, Hill N, Fred HL, Yow EM. Cutaneous manifestations of gonococcemia. A review of 14 cases. Arch Intern Med 1963; 112:731-7.

2. Barlow D. In: Besser M ed Advanced Medicine 13. Tunbridge Wells, England: Pitman Medical Publishing Company Ltd, 1977: 197-203.

3. Holmes KK, Counts GW, Beaty HN. Disseminated gonococcal infection. Ann Intern Med 1971; 74:979-93.

4. Oates JK, Harris JRW. In: Baron DN, Compston N, Dawson AM, eds. Recent Advances in Medicine 17. Edinburgh, London, and New York: Churchill Livingstone, 1977: 155-7.

5. O'Sullivan EP. Gonorrhoea in the skin. Br Med J 1964; ii: 1508. 